\title{
Noise Elimination of Reciprocating Compressors Using FEM, Neural Networks Method, and the GA Method
}

\author{
Ying-Chun CHANG ${ }^{(1)}$, Min-Chie CHIU ${ }^{(2)}$, Ji-Lin XIE $^{(1)}$ \\ (1) Department of Mechanical Engineering \\ Tatung University \\ Taiwan, R.O.C.; e-mail: ycchang@ttu.edu.tw \\ (2) Department of Mechanical and Automation Engineering \\ Chung Chou University of Science and Technology
}

No. 6, Lane 2, Sec.3, Shanchiao Rd., Yuanlin, Changhua 51003, Taiwan, R.O.C.; e-mail: minchie.chiu@msa.hinet.net

(received November 17, 2015; accepted February 27, 2017)

\begin{abstract}
Industry often utilizes acoustical hoods to block noise emitted from reciprocating compressors. However, the hoods are large and bulky. Therefore, to diminish the size of the compressor, a compact discharge muffler linked to the compressor outlet is considered. Because the geometry of a reciprocating compressor is irregular, COMSOL, a finite element analysis software, is adopted. In order to explore the acoustical performance, a mathematical model is established using a finite element method via the COMSOL commercialized package. Additionally, to facilitate the shape optimization of the muffler, a polynomial neural network model is adopted to serve as an objective function; also, a Genetic Algorithm (GA) is linked to the OBJ function. During the optimization, various noise abatement strategies such as a reverse expansion chamber at the outlet of the discharge muffler and an inner extended tube inside the discharge muffler, will be assessed by using the artificial neural network in conjunction with the GA optimizer.

Consequently, the discharge muffler that is optimally shaped will decrease the noise of the reciprocating compressor.
\end{abstract}

Keywords: finite element method; polynomial neural network model; genetic algorithm; group method of data handling; reciprocating compressor; optimization.

\section{Notations}

In this paper the following notations are used: $B_{0}, B_{i}, B_{i j}, B_{i j k}$ - the coefficient of the node function in the ANN,

CPM - the product of the penalty function,

FSE - the deviation of mean square,

$m$ - the number of the design parameters,

$N$ - the number of training data,

$N_{p}$ - the total possible searching number $\left(=2^{m}\right)$,

$Q$ - the number of the network's coefficients,

$x_{i}, x_{j}, x_{k}$ - the input data in the ANN

$y_{k}$ - the output value in the ANN,

$k_{p}$ - the penalty function in the ANN,

$\widehat{y}_{i}$ - the required data in the ANN,

$y_{i}$ - the predicted data for the ANN,

$\sigma p^{2}-$ the error variation in the ANN,

$A 1$ - length of an external reverse expansion chamber $[\mathrm{m}]$,

$B 1$ - length of the connecting tube between the reverse expansion chambers $[\mathrm{m}]$, bit - bit length of chromosome,

iter $_{\max }$ - maximum iteration during GA optimization,

$L_{1}$ - the length of an extended inlet duct inside the discharge muffler $[\mathrm{m}]$,

$L_{2}$ - the length of an extended outlet duct inside the discharge muffler $[\mathrm{m}]$,

$L_{\text {ei }}$ - the length of an inner inlet tube for an external reverse expansion chamber [m],

$L_{\text {eo }}$ - the length of an outer outlet tube for an external reverse expansion chamber $[\mathrm{m}]$

pc - crossover ratio,

pm - mutation ratio,

pop - number of population,

$\mathrm{TL}$ - transmission loss $[\mathrm{dB}]$.

\section{Introduction}

An acoustical hood is often used for traditional noise abatement (Cheremisinoff, Cheremisinoff, 1977), but it is bulky and influences compressor operation due to insufficient space. To overcome this draw- 
back, a compact silencing device connected at the inlet/outlet is used. Research on simple shaped mufflers has been examined using theoretical derivations (CHANG et al., 2004; YEH et al., 2006). However, because of the complicated geometry of the commercial reciprocating compressor, the acoustical assessment using theoretical analysis is not accessible.

SuH et al. (1998) analyzed the acoustical performance of a reciprocating compressor by using a finite element method. DREIMAN et al. (2000) assessed the influence of noise and vibration with respect to a pressure pulse emitted from a reciprocating compressor via a boundary element method analysis. GosAvi et al. (2006) assessed a reciprocating compressor with a revised shape by using the Taguchi method and a boundary element method. Roozen et al. (2009) identified the noise source and implemented the acoustical simulation of a reciprocating compressor using a finite element method. However, the optimization of the muffler's shape has been routinely neglected. CHANG et al. (2009) and Chiu \& CHANG (2009) developed an optimization method for a muffler that had a simple geometrical shape by using a neural network and genetic algorithm. In order to explore an appropriately shaped reciprocating compressor, a commercialized reciprocating compressor which is compact and complicated in shape is assessed. To efficiently reduce the noise emission of the compressor, COMSOL, a commercialized software package that uses a finite element method in conjunction with a neural network method and a genetic algorithm is adopted in this paper.

\section{Mathematical model of the FEM (run on the COMSOL package)}

The boundary condition for the acoustical field of the non-perforated tube (a solid boundary) used in the acoustical model with the COMSOL package is

$$
n \cdot\left\{\frac{1}{\rho_{c}}\left(\nabla p_{t}-q\right)\right\},
$$

where $q$ (a dipole sound source) is set at zero, $c$ (the sound speed) is set at $343 \mathrm{~m} / \mathrm{s}, \rho$ (air density) is set at $1.293 \mathrm{~kg} / \mathrm{m}^{3}$.

Assuming that a plane wave with a sound pressure $(p)$ of $1[\mathrm{~Pa}]$ propagates into the plenum's inlet, the governing equation of the sound wave yields

$$
\nabla \cdot \frac{1}{\rho_{c}}\left(\nabla p_{t}-q\right)+\frac{k_{e q}^{2} p_{t}}{\rho_{c}}=Q,
$$

where

$$
\begin{aligned}
p_{t} & =p+p_{b}, \\
k_{e q}^{2} & =\left(\frac{\omega}{c_{c}}\right)^{2}, \\
c_{c} & =c, \\
\rho_{c} & =\rho .
\end{aligned}
$$

Here, $q$ is a dipole (normally set to be 0 ), $Q$ is a monopole (normally set to be 0 ), $p_{b}$ is the background pressure field.

The Sound Transmission Loss (TL) is calculated as

$$
\mathrm{TL}=10 \log \frac{W_{\text {in }}}{W_{\text {out }}}
$$

where $W_{\text {in }}$ is the inlet sound power and $W_{\text {out }}$ is the outlet sound power.

\section{Model check}

Before performing an acoustical simulation on a reciprocating compressor, an accuracy check of the FEM mathematical model on the fundamental elements of a straight internally tube-extended expansion chamber shown in Fig. 1 was performed using experimental data

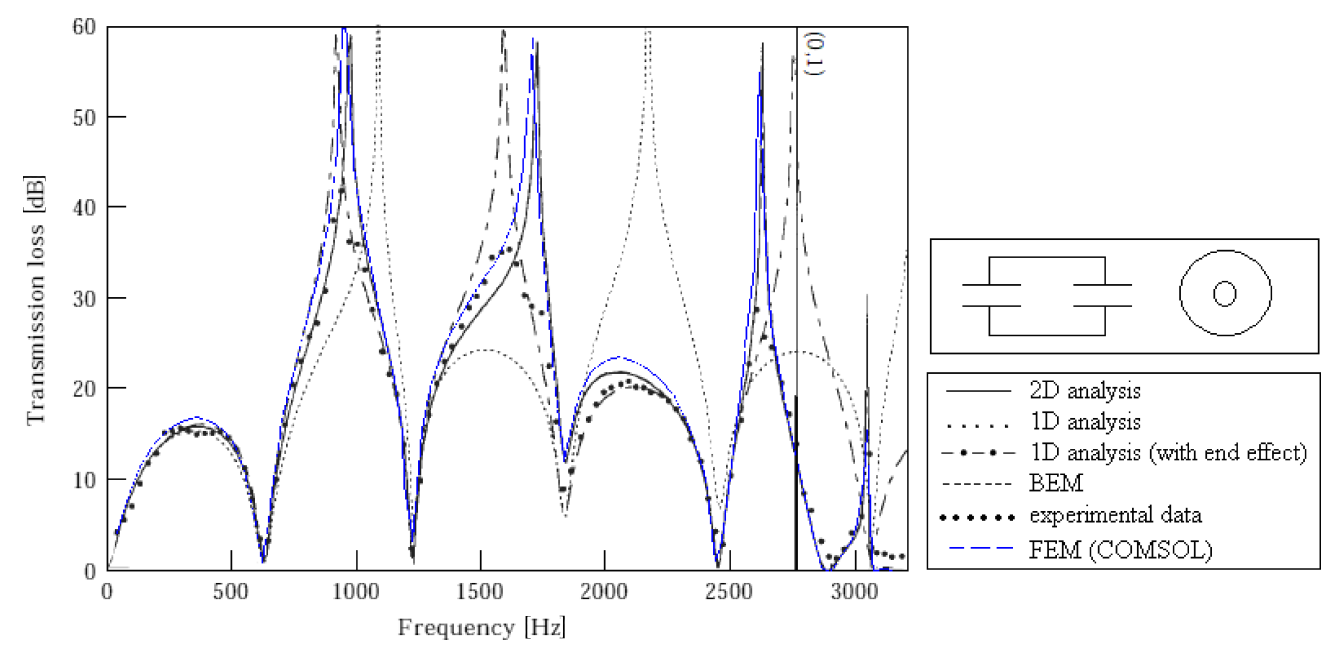

Fig. 1. Accuracy check of a straight internally tube-extended expansion chamber when compared to the Wang theory, experimental data (PAtrikar, Provence, 1996), and COMSOL. 
and analytical data from WANG (1992). As illustrated in Fig. 1, the FEM (run on the COMSOL package) and the analytical data for the muffler are in agreement. Consequently, the simulation and optimization for two kinds of mufflers (muffler A and muffler B) within a fixed space are carried out in the following section.

\section{Sensitivity analysis}

The mechanism of a commercialized reciprocating compressor is depicted in Fig. 2. The flow diagram of the compressor is also illustrated in Fig. 3. In order to investigate the sensitivity of the design parameters, the adjustments of the design parameters are shown in Figs. 4 and 5. The acoustical performances with respect to frequencies using COMSOL (in FEM) are shown in Figs. 6-9. Results in Fig. 6 reveal that in the case of a fixed length of $L_{2}$, the profiles of the TL will be shifted to the left if the length of $L_{1}$ increases. Similarly, as indicated in Fig. 7, in the case of a fixed length of $L_{1}$, the peak value of the TL curve will move up and down when the length of $L_{2}$ varies. In addition, Fig. 8 indicates that the profiles of the TL will shift to the right if the length of $L_{\mathrm{ei}}$ increases. Moreover, as can be seen in Fig. 9, the profiles of the TL will also shift to the right when the length of $L_{\mathrm{oi}}$ increases.

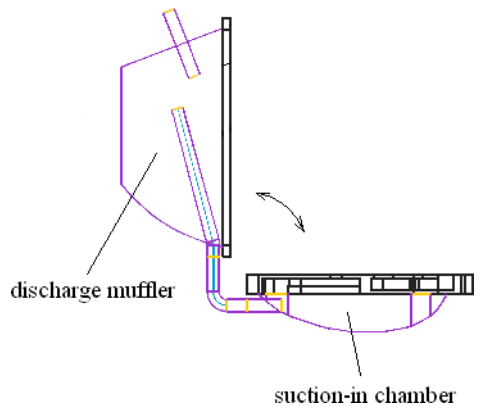

Fig. 2. Mechanism of the reciprocating compressor.

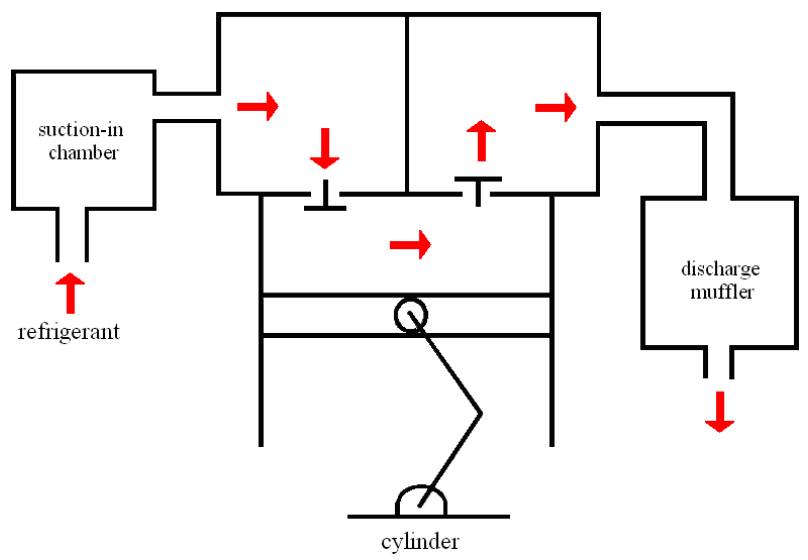

Fig. 3. Flowing diagram for the reciprocating compressor.
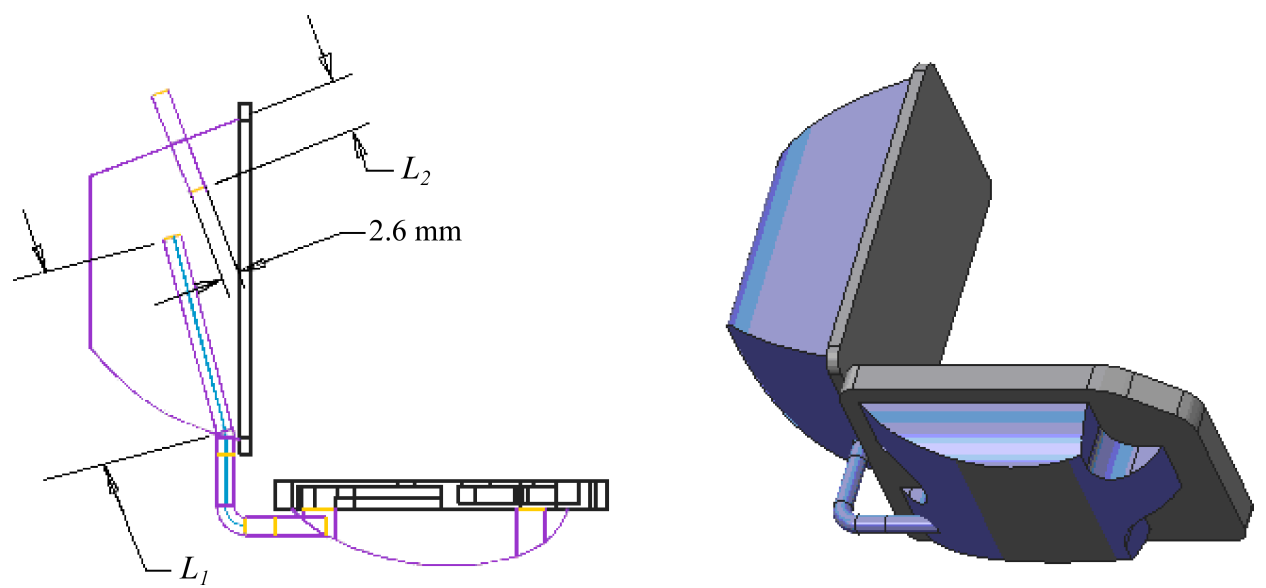

Fig. 4. Mechanism and design parameters for muffler A.

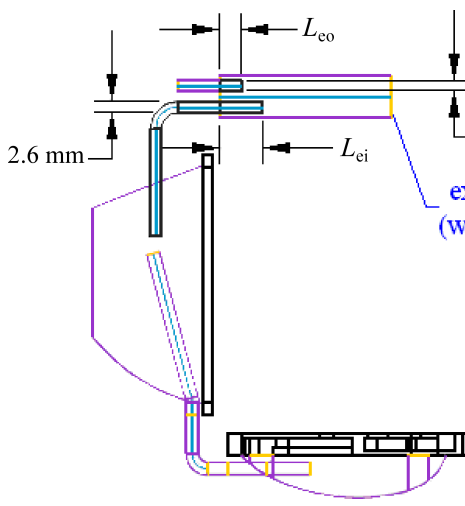

external reverse/expansion chamber (with extended inlet tube/outlet tube)

Fig. 5. Mechanism and design parameters for muffler B. 
Therefore, these design parameters $\left(L_{1}, L_{2}, L_{\mathrm{ei}}\right.$, and $L_{\mathrm{eo}}$ ), which influence the TL curve, are selected as the design parameters in the optimization process.

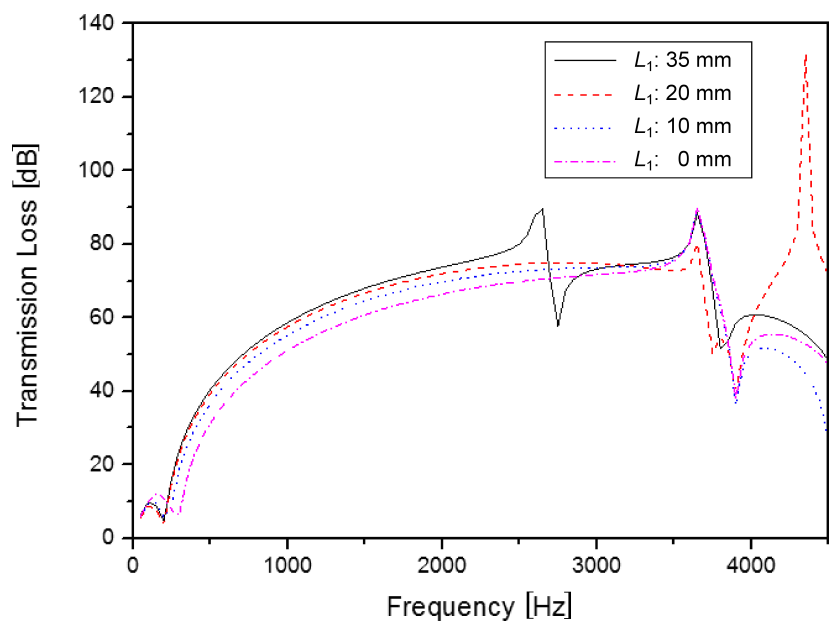

Fig. 6. TL profiles with respect to various values of parameter $L_{1}$ (muffler A).

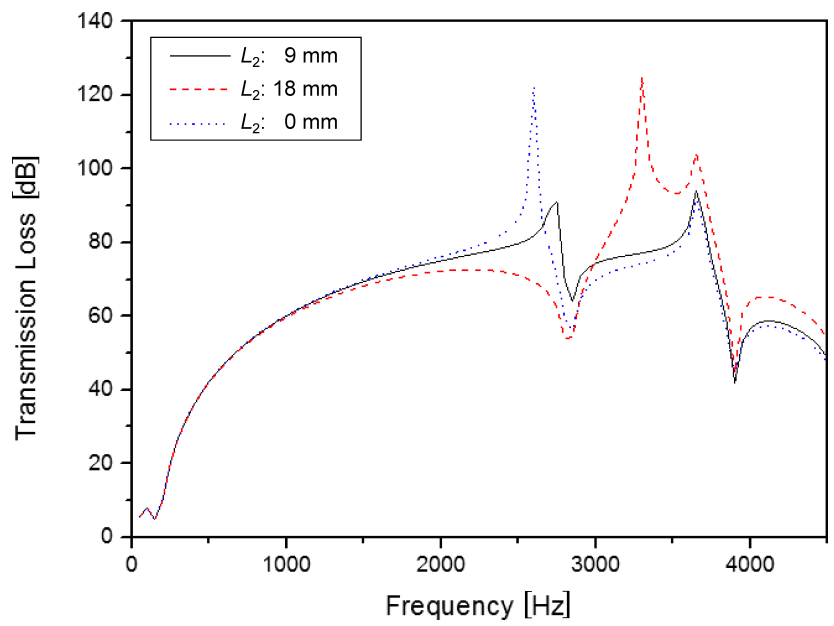

Fig. 7. TL profiles with respect to various values of parameter $L_{2}$ (muffler A).

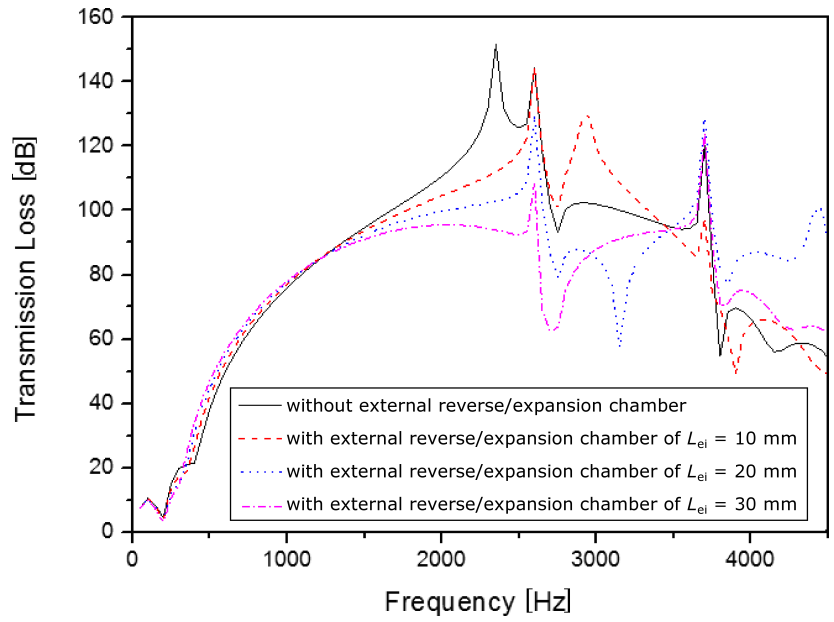

Fig. 8. TL profiles with respect to various values of parameter $L_{\mathrm{ei}}$ (muffler B).

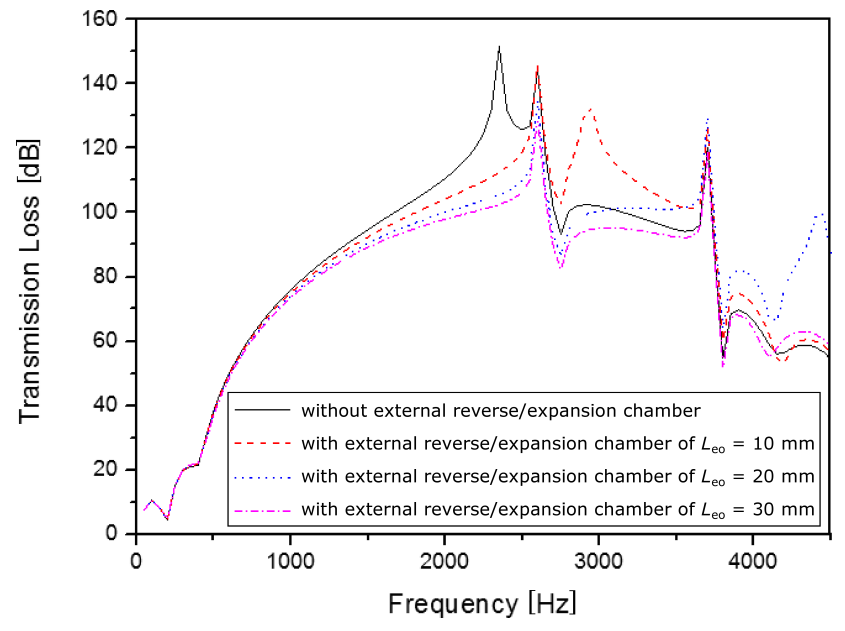

Fig. 9. TL profiles with respect to various values of parameter $L_{\mathrm{eo}}$ (muffler B).

\section{Artificial Neural Network (ANN) model}

Artificial Neural Networks (ANNs) may serve as universal approximators; however, the dependencies are implicit and hidden within the neural network structure. To avoid this inconvenience, an explicit function of a polynomial neural network is adopted. The polynomial neural network developed by IVAKHNENKO (1971); one kind of predictor for fish populations in rivers has been used here. With this, the interconnections between the layers of neurons are simplified, and an automatic algorithm for the structure design and weight adjustment can be built. On the basis of GMDH (Group Method of Data Handling) feed-forward networks and short-term polynomial transfer functions, the coefficients of the polynomial transfer functions can be obtained via a regression process. The regression process will be combined by emulating the selforganizing activity which precedes the artificial neural network's (ANN) structural learning. The polynomial neural network shown in Fig. 10 includes an input layer, a hidden layer $-\Sigma$ (summation), and an output layer (product). Here, the hidden layer is the product

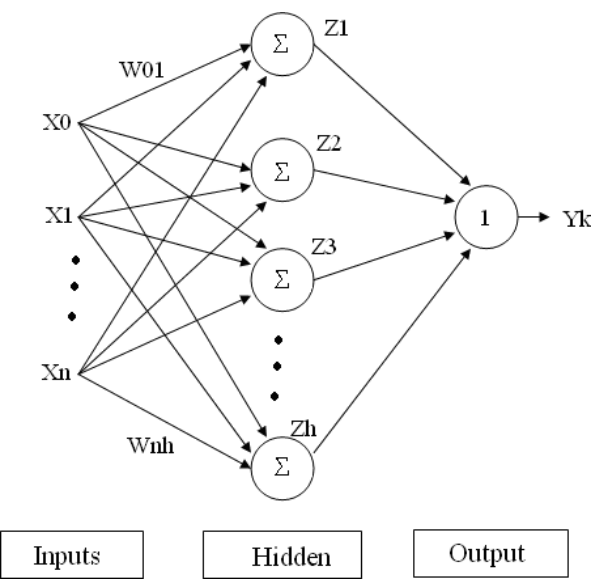

Fig. 10. Structure of an artificial neural network. 
of the input and weighted value (SuH et al., 1998). $z_{j k}$, the $j$-th output, is

$$
z_{j k}=\sum_{i=0}^{n} W_{i j} X_{i j} .
$$

The total output of the neural network yields

$$
y_{k}=\prod_{j=1}^{h} z_{j k},
$$

where $h$ is the unit's number in a hidden layer.

Plugging Eq. (4) into (5) yields

$$
\begin{aligned}
y_{k}= & B_{0}+\sum_{i=1}^{n} B_{i} x_{i}+\sum_{i=1}^{n} \sum_{j=1}^{n} B_{i j} x_{i} x_{j} \\
& +\sum_{i=1}^{n} \sum_{j=1}^{n} \sum_{k=1}^{n} B_{i j k} x_{i} x_{j} x_{k}+\ldots,
\end{aligned}
$$

where $y_{k}$ is the output value, $x_{i}, x_{j}, x_{k}$ are the input data, and $B_{0}, B_{i}, B_{i j}$, and $B_{i j k}$ are the coefficient of the node function.

Two kinds of acoustical devices (muffler A in Fig. 4 and muffler B in Fig. 5) are examples.

For muffler A, using the theoretical data of the FEM as the input data (muffler A: $L_{1}$ and $L_{2}$; muffler B: $L_{\mathrm{ei}}$ and $L_{\mathrm{eo}}$ ) and the output data (TL) in the proposed ANN (Artificial Neural Network) model, a trained ANN model can be achieved using both the training data bank and the polynomial calculation in conjunction with the PSE standard (deviation of mean square) where PSE is in the form of

$$
\begin{aligned}
\mathrm{PSE} & =\mathrm{FSE}+k_{p}, \\
\mathrm{FSE} & =\frac{1}{N} \sum_{i=1}^{N}\left(\widehat{y}_{i}-y_{i}\right)^{2}, \\
k_{p} & =\mathrm{CMP} \frac{2 \sigma p^{2} Q}{N} .
\end{aligned}
$$

Here, FSE is the deviation of the mean square, $k_{p}$ is the penalty function, $N$ is the number of training data, $\widehat{y}_{i}$ is the required data, $y_{i}$ is the predicted data for the

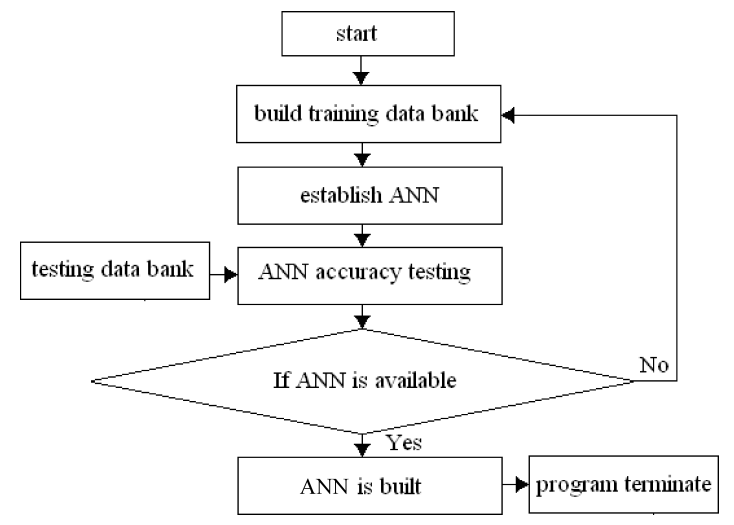

Fig. 11. Steps in the ANN model.
ANN model, CPM is the product of the penalty function, $\sigma p^{2}$ is the error variation, and $Q$ is the number of the network's coefficients.

The flow diagram of the ANN model is depicted in Fig. 11. The predicted TL can be obtained by inputting arbitrary design data into the ANN model, a simplified OBJ function. With this, the optimal process of the mufflers can be performed by using the ANN model and the GA method.

\section{Genetic Algorithm}

Genetic Algorithms (GA) were first formalized by Holland (1975) and later developed and applied in functional optimization by JoNG (1975). Based on the concept of Darwinian natural selection, GA's search strategies involve population size, selection method, mutation ratio, crossover ratio, maximum iteration, parameter numbers, length of the chromosome, and searching ranges of the parameters. Each new candidate parent will be selected by the coding/decoding transformation and the fitness (i.e. objective function) calculation. The precision $(M)$ of the parameter search is

$$
M=\frac{P_{\max }-P_{\min }}{N_{p}-1},
$$

where $N_{p}\left(=2^{m}\right)$ is the total possible searching number, $m$ is the number of the design parameters, $P_{\max }$ is the maximum range of the parameter, and $P_{\min }$ is the minimum range of the parameter. Here, the tournament selection serves as the elitism mechanism in the GA optimization. Also, the uniform crossover is adopted in the optimization process. Moreover, in order to generate a better offspring, the range of the chromosome will be widened by using a mutation scheme. The GA operations are illustrated in Fig. 12. The process was terminated when the number of generations reached a pre-selected iter $\max$.

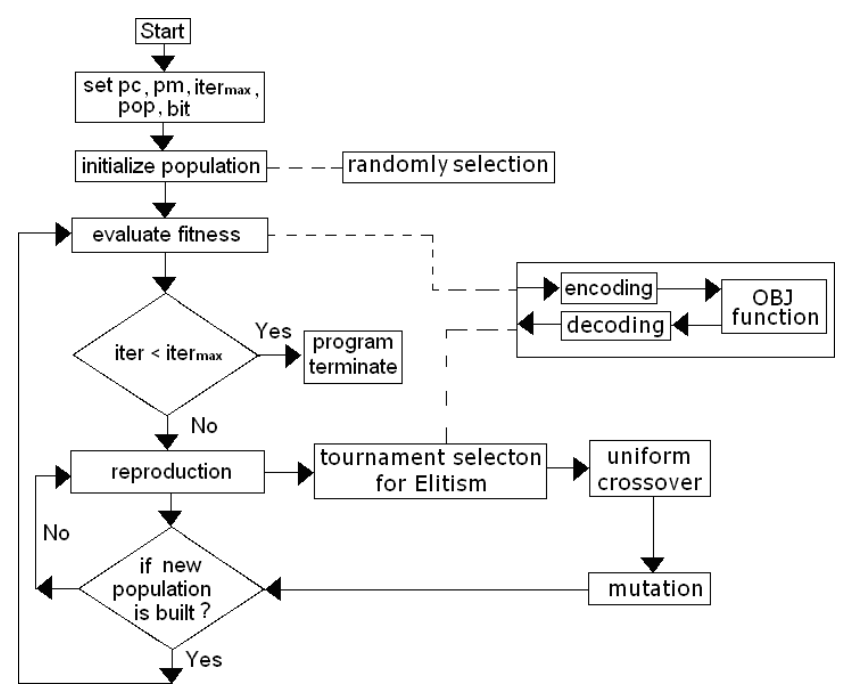

Fig. 12. GA optimization flow diagram. 


\section{Case study}

Two kinds of acoustical devices (muffler A in Fig. 4 and muffler B in Fig. 5) are considered for reducing the targeted tones of $2750 \mathrm{~Hz}$ and $2950 \mathrm{~Hz}$, respectively. As indicated in Fig. 4, the length of the extended inlet tube inside the discharge muffler is set at $L_{1}$ and the extended outlet tube inside the discharge muffler is set at $L_{2}$ when muffler $\mathrm{A}$ is used in the noise elimination. Similarly, as indicated in Fig. 5, the length of the inner extended inlet tube inside the reverse expansion chamber is set at $L_{\mathrm{ei}}$ and the inner extended outlet tube inside the reverse expansion chamber is set at $L_{\mathrm{eo}}$ when muffler $\mathrm{B}$ is used in the noise elimination.

\subsection{Muffler $A$}

To optimize the acoustical performance within a limited space, two kinds of design parameters $-L_{1}$

Table 1. The range and schedule levels of the parameters (muffler A).

\begin{tabular}{|c|c|c|r|r|r|r|c|}
\hline $\begin{array}{c}\text { Design } \\
\text { parameters }\end{array}$ & $\begin{array}{c}\text { Min } \\
{[\mathrm{mm}]}\end{array}$ & $\begin{array}{c}\text { Max } \\
{[\mathrm{mm}]}\end{array}$ & \multicolumn{5}{|c|}{5 level [mm] } \\
\hline$L_{1}$ & 30 & 40 & 30 & 32.5 & 35 & 37.5 & 40 \\
\hline$L_{2}$ & 9 & 21 & 9 & 12.0 & 15 & 18.0 & 21 \\
\hline
\end{tabular}

Table 2. TL with respect to twenty-five training data sets (muffler A).

\begin{tabular}{|c|c|c|}
\hline No. of exp. & $L_{\text {in }}[\mathrm{mm}]$ & $L_{\text {out }}[\mathrm{mm}]$ \\
\hline 1 & 30.0 & 9 \\
\hline 2 & 30.0 & 12 \\
\hline 3 & 30.0 & 15 \\
\hline 4 & 30.0 & 18 \\
\hline 5 & 30.0 & 21 \\
\hline 6 & 32.5 & 9 \\
\hline 7 & 32.5 & 12 \\
\hline 8 & 32.5 & 15 \\
\hline 9 & 32.5 & 18 \\
\hline 10 & 32.5 & 21 \\
\hline 11 & 35.0 & 9 \\
\hline 12 & 35.0 & 12 \\
\hline 13 & 35.0 & 15 \\
\hline 14 & 35.0 & 18 \\
\hline 15 & 35.0 & 21 \\
\hline 16 & 37.5 & 9 \\
\hline 17 & 37.5 & 12 \\
\hline 18 & 37.5 & 15 \\
\hline 19 & 37.5 & 18 \\
\hline 20 & 37.5 & 21 \\
\hline 21 & 40.0 & 9 \\
\hline 22 & 40.0 & 12 \\
\hline 23 & 40.0 & 15 \\
\hline 24 & 40.0 & 18 \\
\hline 25 & 40.0 & 21 \\
\hline
\end{tabular}

and $L_{2}-$ are chosen as the tuned variables. The range and schedule levels of the parameters are depicted in Table 1. Therefore, using the FEM run on the COMSOL package, the TL with respect to twenty-five training data sets shown in Table 2 is calculated. Taking $L_{1}$ and $L_{2}$ as the input data and the resulting TL as the output data in the ANN model and inputting a series of training data into the ANN model system, the fitness functions of the targeted frequency of $2750 \mathrm{~Hz}$ is established and shown below.

\subsubsection{Target frequency $-2750 \mathrm{~Hz}$}

$$
\begin{aligned}
\mathrm{N}_{2750}= & -9.69948+0.277128 \cdot L_{1} \\
\mathrm{~N} 2_{2750}= & -3.4641+0.23094 \cdot L_{2} \\
\mathrm{~N} 3_{2750}= & -0.44721+0.465843 \cdot \mathrm{N} 1_{2750}^{2} \\
\mathrm{~N} 4_{2750}= & 1.00282+1.52496 \cdot \mathrm{N} 3_{2750} \\
& -1.33402 \cdot \mathrm{N} 2_{2750}-5.47798 \cdot \mathrm{N} 3_{2750}^{2} \\
& -0.245745 \cdot \mathrm{N} 2_{2750}^{2} \\
& +0.568317 \cdot \mathrm{N} 3_{2750} \cdot \mathrm{N} 2_{2750} \\
& +0.478358 \cdot \mathrm{N} 2_{2750}^{3} \\
\mathrm{TL}_{2750}= & 70.445+11.3277 \cdot \mathrm{N} 4_{2750}
\end{aligned}
$$

\subsection{Muffler B}

Similarly, to optimize the acoustical performance within a limited space, two kinds of design parameters $-L_{\mathrm{ei}}$ and $L_{\mathrm{eo}}-$ are chosen as the tuned variables. The range and schedule levels of the parameters are depicted in Table 3. Therefore, using the FEM run on the COMSOL package, the TL with respect to twentyfive training data sets shown in Table 4 is calculated. Taking $L_{\mathrm{ei}}$ and $L_{\mathrm{eo}}$ as the input data and the resulting TL as the output data in the ANN model and inputting a series of training data into the ANN model system, the fitness functions of the targeted frequency of $2950 \mathrm{~Hz}$ is established and shown below.

Table 3. The range and schedule levels of the parameters (muffler B).

\begin{tabular}{|c|c|c|c|c|c|c|}
\hline $\begin{array}{c}\text { Original } \\
\text { dimension }\end{array}$ & $\begin{array}{c}\text { Min } \\
{[\mathrm{mm}]}\end{array}$ & $\begin{array}{c}\text { Max } \\
{[\mathrm{mm}]}\end{array}$ & \multicolumn{4}{|c|}{4 level [mm] } \\
\hline$L_{\mathrm{ei}}$ & 0 & 15 & 0 & 5 & 10 & 15 \\
\hline$L_{\mathrm{eo}}$ & 0 & 15 & 0 & 5 & 10 & 15 \\
\hline
\end{tabular}

\subsubsection{Target frequency $-2950 \mathrm{~Hz}$}

$$
\begin{aligned}
& \mathrm{N} 1_{2950}=-1.29904+0.173205 \cdot L_{1}, \\
& \mathrm{~N} 2_{2950}=-1.29904+0.173205 \cdot L_{2},
\end{aligned}
$$


Table 4. TL with respect to twenty-five training data sets (muffler B).

\begin{tabular}{|c|c|c|}
\hline No. of exp. & $L_{1}[\mathrm{~mm}]$ & $L_{2}[\mathrm{~mm}]$ \\
\hline 1 & 0 & 0 \\
\hline 2 & 0 & 5 \\
\hline 3 & 0 & 10 \\
\hline 4 & 0 & 15 \\
\hline 5 & 5 & 0 \\
\hline 6 & 5 & 5 \\
\hline 7 & 5 & 10 \\
\hline 8 & 5 & 15 \\
\hline 9 & 10 & 0 \\
\hline 10 & 10 & 5 \\
\hline 11 & 10 & 10 \\
\hline 12 & 10 & 15 \\
\hline 13 & 15 & 0 \\
\hline 14 & 15 & 5 \\
\hline 15 & 15 & 10 \\
\hline 16 & 15 & 15 \\
\hline
\end{tabular}

$$
\begin{aligned}
\mathrm{N} 3_{2950}= & 1.0355+0.587243 \cdot \mathrm{N}_{2950} \\
& -0.693328 \cdot \mathrm{N} 2_{2950} \\
& -0.572918 \cdot \mathrm{N} 1_{2950}^{2}-0.531615 \cdot \mathrm{N} 2_{2950}^{2} \\
& -0.201774 \cdot \mathrm{N}_{2950} \cdot \mathrm{N} 2_{2950} \\
& -0.495696 \cdot \mathrm{N} 1_{2950}^{3} \\
& -0.479031 \cdot \mathrm{N} 2_{2950}^{3} \\
\mathrm{~N} 4_{2950}= & 1.84374 \cdot \mathrm{N} 3_{2950}-0.573725 \cdot \mathrm{N} 3_{2950}^{3} \\
\mathrm{~N}_{2950}= & -0.57432+0.616243 \cdot \mathrm{N} 4_{2950}^{2} \\
& +0.725829 \cdot \mathrm{N} 4_{2950}^{3} \\
\mathrm{TL}_{2950}= & 113.693+17.7842 \cdot \mathrm{N} 5_{2950} .
\end{aligned}
$$

\section{Results and discussion}

\subsection{Results}

By using the trained ANN model in conjunction with the GA optimizer, an optimized design is obtained and shown in Table 5. Plugging the original data and the optimal design data into COMSOL, the TL profiles before and after optimization was performed are plotted in Fig. 13. The best GA set is (pop, bit, iter $\max$, $\mathrm{pc}, \mathrm{pm})=(100,20,500,0.6,0.5)$. As can be seen in Fig. 13, the TLs of muffler A at a targeted frequency

Table 5. The range and level of the design parameters (muffler A).

\begin{tabular}{|c|c|c|}
\hline & $L_{1}[\mathrm{~mm}]$ & $L_{2}[\mathrm{~mm}]$ \\
\hline Original dimension & 35.00 & 9.00 \\
\hline $\begin{array}{c}\text { Optimal dimension } \\
\text { targeted tone: } 2750 \mathrm{~Hz}]\end{array}$ & 38.91 & 11.64 \\
\hline
\end{tabular}

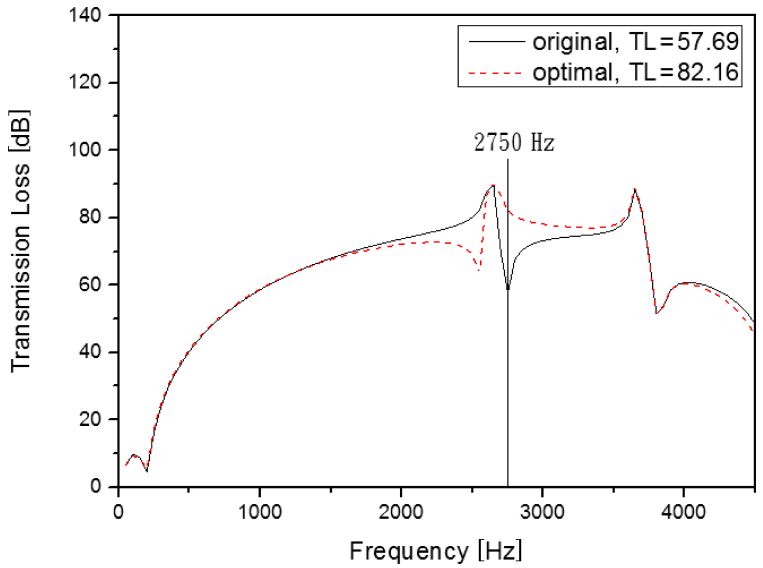

Fig. 13. TL before and after optimization at the targeted tone of $2750 \mathrm{~Hz}$ (muffler A).

of $2750 \mathrm{~Hz}$ before and after performing an optimization are $57.69 \mathrm{~dB}$ and $82.16 \mathrm{~dB}$. Similarly, using the same GA control parameters for muffler B's shape optimization, the resulting design data is shown in Table 6 . The TL profiles before and after optimization was performed are plotted in Fig. 14. As can be seen in Fig. 14, the TLs of muffler B at a targeted frequency of $2950 \mathrm{~Hz}$ before and after performing an optimization are $130.01 \mathrm{~dB}$ and $150.17 \mathrm{~dB}$.

Table 6 . The range and level of the design parameters (muffler B).

\begin{tabular}{|c|c|c|}
\hline & $L_{\mathrm{ei}}[\mathrm{mm}]$ & $L_{\mathrm{eo}}[\mathrm{mm}]$ \\
\hline Original dimension & 10.00 & 0.00 \\
\hline $\begin{array}{c}\text { Optimal dimension } \\
\text { targeted tone: } 2950 \mathrm{~Hz}]\end{array}$ & 10.12 & 5.06 \\
\hline
\end{tabular}

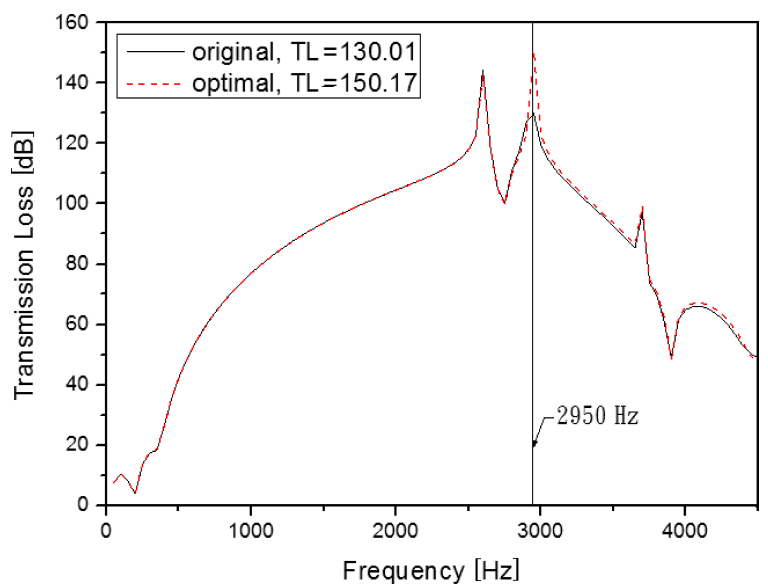

Fig. 14. TL before and after optimization at the targeted tone of $2950 \mathrm{~Hz}$ (muffler B).

The accuracy checks of the ANN model for muffler A (at $2750 \mathrm{~Hz}$ ) and muffler B (at $2950 \mathrm{~Hz}$ ) have been verified by using the COMSOL package. The results for muffler A and muffler B are depicted in Table 7 and Table 8, respectively. As indicated in Table 7, 
Table 7. The accuracy check of ANN model (muffler A).

\begin{tabular}{|c|c|c|}
\hline & TL [dB] & Error [\%] \\
\cline { 1 - 2 } Optimal TL[ANN] at $2750 \mathrm{~Hz}$ & 89.92 & \multirow{2}{*}{8.62} \\
\cline { 1 - 2 } Optimal TL[COMSOL] at $2750 \mathrm{~Hz}$ & 82.16 & \\
\hline \multicolumn{2}{|c|}{ error $=\frac{\mathrm{TL}(\mathrm{COMSOL})-\mathrm{TL}(\mathrm{ANN})}{\mathrm{TL}(\mathrm{ANN})} * 100 \%$} \\
\hline
\end{tabular}

Table 8. The accuracy check of ANN model (muffler B).

\begin{tabular}{|c|c|c|}
\hline & TL [dB] & Error [\%] \\
\cline { 1 - 2 } Optimal TL[ANN] at $2950 \mathrm{~Hz}$ & 147.793 & \multirow{2}{*}{1.49} \\
\cline { 1 - 2 } Optimal TL[COMSOL] at $2950 \mathrm{~Hz}$ & 150.171 & \\
\hline \multicolumn{2}{|c|}{ error $=\frac{\mathrm{TL}(\mathrm{COMSOL})-\mathrm{TL}(\mathrm{ANN})}{\mathrm{TL}(\mathrm{ANN})} * 100 \%$} \\
\hline
\end{tabular}

the accuracy of the ANN model in muffler A reaches $8.62 \%$. Likewise, as illustrated in Table 8, the accuracy of the ANN model in muffler B reaches $1.49 \%$.

\subsection{Discussion}

In order to simplify the numerical assessment of a reciprocating compressor with a complicated shape, a finite element model (FEM) used in predicting the muffler's TL is adopted. Moreover, to find an optimally shaped muffler, a simplified objective function (OBJ) with respect to the muffler at specified tones is established by linking the finite element model (FEM) with the artificial neural network (ANN) model.

As described in Sec. 4, for muffler A, the influence of the TL with respect to parameters $L_{1}$ and $L_{2}$ shown in Figs. 6 and 7 is substantial. Also, for muffler B, the influence of the TL with respect to parameters $L_{\mathrm{ei}}$ and $L_{\mathrm{eo}}$ shown in Figs. 8 and 9 is also substantial. Therefore, two sets of design parameters - $\left(L_{1}, L_{2}\right)$ for muffler $\mathrm{A}$ and $\left(L_{\mathrm{ei}}, L_{\mathrm{eo}}\right)$ for muffler $\mathrm{B}$ - are adopted in the optimization process. The numerical results of muffler A and muffler B shown in Figs. 13 and 14 also indicates that the optimized TLs are precisely located at the targeted frequencies of $2750 \mathrm{~Hz}$ and $2950 \mathrm{~Hz}$. Figure 13 indicates that the noise reduction of muffler A can be improved by $24.47 \mathrm{~dB}$ after optimization is performed. Similarly, as indicated in Fig. 14, the noise reduction of muffler $\mathrm{B}$ can be improved by $20.16 \mathrm{~dB}$ after optimization is carried out. Moreover, as indicated in Tables 7 and 8, the accuracy check between the ANN model and the FEM is between 1.49$8.62 \%$. Therefore, the assessment of optimally shaped muffler $\mathrm{A}$ and muffler $\mathrm{B}$ used in a reciprocating compressor is valid.

As can be seen in Figs. 13 and 14, the TL's broadband of muffler A and B is similar. However, the profile's peak value of muffler B is better than that of the muffler A.

\section{Conclusion}

Sensitivity analysis reveals that muffler A's design parameters of an inner extended inlet tube's length $\left(L_{1}\right)$ and an inner extended outlet tube's length $\left(L_{2}\right)$ are essential. Also, muffler B's design parameters of an inner extended inlet tube's length $\left(L_{\mathrm{ei}}\right)$ and an inner extended outlet tube's length $\left(L_{\mathrm{eo}}\right)$ are important in the shape optimization process. To speed up the optimization for a reciprocating compressor that has a complicated shape, a simplified OBJ function using a FEM model (run on COMSOL) in conjunction with a neural network (ANN) model is built. After the training and testing for the ANN model, the optimization process will be performed by linking the ANN model with the GA optimizer. Results reveal that muffler A and muffler B can be precisely optimized at a targeted frequency using the ANN model in concert with the GA method by adjusting the mufflers' shape under certain space constraints. In addition, muffler A and B's TL's broadband are similar. Note though, the profile's peak value of the TL will increase when using muffler B.

Consequently, the study proposed in this paper can provide a quick and easy way to reduce noise emitted from a reciprocating compressor that has a complicated shape.

\section{References}

1. Chang Y.C., Chiu M.C., Cheng M.M. (2009), Optimum design of perforated plug mufflers using neural network and genetic algorithm, Proc. ImechE Part C: Journal of Mechanical Engineering Science, 223, 935952 .

2. Chang Y.C., Yeh L.J., Chiu M.C. (2004), Numerical studies on constrained venting system with side inlet/outlet mufflers by GA optimization, Acta Acustica united with Acustica, 1, 1-11.

3. Cheremisinoff P.N., Cheremisinoff P.P. (1977), Industrial noise control handbook, Ann Arbor Science, Michigan.

4. Chiu M.C., Chang Y.C. (2009), Application of neural network and genetic algorithm to the optimum design of perforated tube mufflers, J. of Mechanics, 25, N7N16.

5. Dreiman N., Collings D., Flora M.D. (2000), Noise reduction of fractional horse power hermetic reciprocating compressor, International Compressor Engineering Conference.

6. Gosavi S.S., Juge V.M., Nadgouda M.M. (2006), Optimization of suction muffler using Taguchi's method, International Compressor Engineering Conference.

7. Holland J. (1975), Adaptation in natural and artificial system, Ann Arbor: University of Michigan Press. 
8. Ivakhnenko A.G. (1971), Polynomial theory of complex system, IEEE Trans. Syst. Man. Cyber., 1, 4, 364368 .

9. Jong D. (1975), An analysis of the behavior of a class of genetic adaptive systems, Doctoral thesis, Dept. Computer and Communication Sciences, Ann Arbor, University of Michigan.

10. Patrikar A., Provence J. (1996), Nonlinear system identification and adaptive control using polynomial networks, Math. Comput. Modeling, 23, 1-2, 159173.

11. Roozen N.B., Oetelaar V.D.J., Geerlings A., Vliegenthart T. (2009), Source identification and noise reduction of a reciprocating compressor; a case history, International Journal of Acoustics and Vibration, 14, 2, 90-98.

12. Suh K.H., Lee H., OH W.S., Jung W.H. (1998), An analysis of the hermetic reciprocating compressor acoustic system, International Compressor Engineering Conference.

13. WANG C.N. (1992), The application of boundary element method in the noise reduction analysis for the automotive mufflers, Ph.D Thesis, Taiwan University.

14. Yeh L.J., Chang Y.C., Chiu M.C. (2006), Numerical studies on constrained venting system with reactive mufflers by GA optimization, International Journal for Numerical Methods in Engineering, 65, 1165-1185. 